\title{
ANÁLISE DOS ESPAÇOS DE EQUILÍBRIO AMBIENTAL DA REGIÃO CENTRAL DE VILA VELHA-ES.
}

\section{ANALYSIS OF THE ENVIRONMENTAL EQUILIBRIUM SPACES OF THE CENTRAL REGION OF VILA VELHA-ES.}

\author{
Larissa Leticia Andara Ramos \\ Patrícia Scarpat Thompson Palhano \\ Suzany Rangel Ramos
}

\begin{abstract}
RESUMO
A cidade de Vila Velha passou por um processo de urbanização acelerado que, juntamente com a falta de planejamento urbano e a valorização imobiliária, substituiu ambientes naturais por espaços construídos que não favorecem a saúde e a qualidade de vida da população. Nesse contexto, o presente artigo objetiva analisar os espaços verdes, considerados neste trabalho como "espaços de equilíbrio ambiental" da Região Central do município. A metodologia baseou-se no mapeamento das áreas, considerando Mendonça (2015), com auxílio do programa ArcGIS, tendo como referência o plano diretor, imagem de satélite e visitas locais. A análise constatou que os espaços de equilíbrio ambiental não são bem distribuídos e são concentrados nas Áreas de Preservação Permanente. Destaca-se ainda a importância dos espaços potenciais que podem ser utilizados para suprir a carência dessas áreas. Esperase, assim, contribuir para novas pesquisas e futuras intervenções nos espaços livres da cidade.
\end{abstract}

Palavras-Chave: Espaço Público. Vivência urbana. Áreas verdes. Espaços de Equilíbrio Ambiental.

\section{ABSTRACT}

The city of Vila Velha underwent a process of accelerated urbanization that, together with the lack of urban planning and real estate valuation, replaced natural environments with built spaces that do not favor the health and quality of life of the population. In this context, this article aims to analyze the green spaces, considered in this work as "spaces of environmental equilibrium" of the Central Region of the municipality. The methodology was based on the mapping of the areas, considering Mendonça (2015), with the aid of the ArcGIS program, with reference to the master plan, satellite image and local visits. The analysis found that the spaces of environmental equilibrium of the Regional are not well distributed and are concentrated in the areas of permanent preservation (APPs). It is also noteworthy the importance of potential spaces that can be used to supply the shortage of these areas. Thus, it ishoped to contribute to further research and future interventions in the free spaces of the city.

Key Words: Public Space. Urban Experience. Green Areas. Environmental Equilibrium Spaces. 


\section{INTRODUÇÃo}

As cidades são formas de vida coletiva e lugar da coexistência, onde a pluralidade parte da convivência entre atores socialmente diferentes (NETTO et al, 2017). Essa estrutura, ao promover o encontro e a interação humana, produz vitalidade, fator essencial à experiência da vida urbana. Essa experiência do mundo e do outro é a base para a compreensão da urbanidade, que pode ser diferentemente experimentada de acordo com as condições materiais, ambientais e sociais impostas pela espacialidade local.

De acordo com Aguiar e Netto (2012), a urbanidade é definida como civilidade do convívio urbano e deve ser entendida como uma experiência, sendo um fenômeno resultante do relacionamento entre o espaço e o ser humano, que depende da morfologia da cidade. Na cidade contemporânea, a relação entre homem e meio urbano é prejudicada a cada dia, à medida que o planejamento urbano dominante trata a cidade como uma estrutura monótona e opressiva, não priorizando à criação de espaços livres de uso público, que de fato consolidam a cidade como um local de encontro (SHULTZ, 2008).

Para Nucci (2008), o modelo de cidade atual ignora o fato da sociedade depender do meio biofísico para sobreviver, ao passo que o uso da terra é ditado pelos interesses econômicos. A proposta de cidade adensada não se importa com a qualidade ambiental e com outras necessidades como quantidade, qualidade e distribuição de espaços livres que permitem a sociabilização e a vivência urbana de forma saudável. Mascaró (2012) afirma que a urbanização tradicional é baseada na infraestrutura cinza monofuncional, onde toda infraestrutura urbana é voltada para a criação de edifícios e ruas que visam a circulação de veículos. O contrário dessa realidade seria a infraestrutura verde, que consiste em redes multifuncionais de espaços permeáveis e arborizados que reestruturam a paisagem urbana.

Neste cenário, com a modificação de ambientes naturais - a partir do adensamento dos edifícios, da concentração de indústrias, da abertura de vias, da impermeabilização do solo, da redução dos espaços livres e das áreas verdes, dentre outras ações impactantes do uso do solo, - o conforto ambiental nas cidades é modificado, alterando o microclima local e a qualidade do ar, gerando poluição sonora, aumento de temperaturas e de consumo energético. Além dos efeitos na saúde da população, os efeitos sociais também são evidenciados. O adensamento das cidades brasileiras e a carência de espaços livres resultam em cidades sem espaços para o convívio e troca de experiências, contribuindo para instauração de uma sociedade passiva e sem urbanidade.

A boa qualidade do espaço urbano está relacionada com a experiência da escala humana, onde as pessoas encontramse de perto com a cidade. Para Gehl (2015), as cidades devem propiciar boas condições para caminhar, parar, sentar, olhar, ouvir e falar. Para que essas experiências sejam vividas de forma plena, os espaços públicos da cidade devem oferecer atributos como acessibilidade, conforto, usos atrativos e permeabilidade no tecido urbano (ANDRADE e LINKE, 2017).

A qualidade ambiental das cidades também inclui como fator de avaliação as áreas verdes, e a ausência desses espaços interfere negativamente na qualidade de vida da população. Lima e Amorim (2006) destacam que um ambiente com qualidade requer a presença da vegetação e esta interfere positivamente na qualidade de vida urbana.

A cidade de Vila Velha, estado do Espirito Santo (município estudo deste trabalho) carece de uma visão sistêmica que integre as áreas verdes no espaço urbano, interagindo com a população. A falta de planejamento, o adensamento populacional e o processo de urbanização resultaram na substituição de ambientes naturais por espaços construídos. Este cenário, atinge negativamente o meio ambiente urbano e consequentemente a saúde das pessoas, ao diminuir as áreas verdes urbanas. Nesse sentido, percebendo as falhas no ordenamento da cidade de Vila Velha que resultaram na carência de espaços verdes, é que se compreende a necessidade de identificá-los e quantificá-los, buscando evidenciar a fragilidade do sistema e, assim, destacar 
a urgência de intervenções na qualidade ambiental urbana do município. Para isso, pretende-se com este artigo, apresentar uma análise crítica dos espaços de equilíbrio ambiental e dos espaços potenciais presentes da Região Central do município Vila Velha - ES.

Foram necessárias, para realização deste trabalho, leituras de bibliografias referentes ao tema, com foco nos espaços de equilíbrio ambiental, a fim de compreender a importância das áreas verdes para a vivência urbana. A identificação das áreas foi realizada a partir de imagens de satélite disponibilizadas pelo programa Google Earth, confrontando as informações presentes no Plano Diretor Municipal de Vila Velha (VILA VELHA, 2007) e visitas locais.

O mapeamento das áreas foi desenvolvido no programa ArcGIS de geoprocessamento, com base cartográfica digital georreferenciada, com legendas de identificação específicas. As áreas mapeadas foram identificadas segundo Mendonça (2015) que classifica os espaços livres de usos público em três grupos: espaços livres públicos de equilíbrio ambiental; espaços livres públicos de práticas sociais e espaços livres potenciais. Ressaltase neste trabalho, a análise de dois grupos consolidados: espaços livres públicos de equilíbrio ambiental e espaços livres potenciais.

De acordo com Mendonça (2015), os espaços livres de equilíbrio ambiental, foco desta pesquisa, compreendem as áreas cobertas de vegetação de significativo valor paisagístico ambiental que na cidade de Vila Velha correspondem as Zonas de Especiais de Interesse Ambiental (VILA VELHA, 2008) englobando as Áreas de Preservação Permanente (APPs), as Unidades de Conservação e demais áreas verdes de potencial paisagístico (AVPP). Os espaços potenciais englobam, em especial, as áreas privadas que apresentam potencial de transformação em áreas de equilíbrio ambiental ou de práticas sociais, devido as suas características e localização na malha urbana (MENDONÇA, 2015).

Com as áreas identificadas e mapeadas foi possível realizar análises e comparações gerais entre as informações coletadas, inclusive calculando Índices de Áreas Verdes (IAV) da Regional, combinando diferentes cenários. Os resultados foram ilustrados com tabelas, mapas e gráficos, visando quantificar e compreender a influência dessas áreas.

\section{2 Áreas Verdes e a Vivência Urbana}

A urbanidade é definida pela experiência do indivíduo num determinado ambiente urbano. Essa experiência pode ser vivenciada de forma plena quando as intervenções urbanas são realizadas na escala humana. De acordo com Gehl (2015), a cidade deve oferecer conforto e atrair as pessoas para utilizarem os espaços públicos durante todo o dia, fornecendo experiências estéticas e impressões sensoriais agradáveis. É importante ressaltar que existem inúmeros critérios que, quando combinados, validam uma experiência urbana de boa qualidade, todavia, o presente artigo enfatiza o estudo das áreas verdes.

Considerando os " 12 critérios de qualidade com respeito à paisagem do pedestre" descritos por Gehl (2015, p. 239), as áreas verdes, em sua abrangência de elementos, contribuem diretamente para o prazer, conforto e proteção do indivíduo em sua vivência urbana, além de serem fundamentais no estímulo à apropriação e participação do ser humano na dinâmica da cidade.

A Resolução 369/2006, art. $8^{\circ}, \S 1^{\circ}$ (BRASIL, 2006) define área verde como "o espaço de domínio público que desempenha função ecológica, paisagística e recreativa, propiciando a melhoria da qualidade estética, funcional e ambiental da cidade, sendo dotado de vegetação e espaços livres de impermeabilização". Lima et al (1994) definem como local com predominância de vegetação arbórea que engloba praças, jardins públicos e parques urbanos, além de canteiros centrais e vias públicas, mesmo que possua apenas funções estéticas. Para Mascaró (2008), essas áreas podem ser classificadas em dois grandes grupos: a) área verde principal, formada por parques, hortas e floriculturas e b) área verde secundária que são as praças, largos e ruas arborizadas. 
A vegetação é um dos componentes necessários para a construção de um bom espaço urbano. Além da função paisagística, diversas são as suas atribuições nos aspectos ambientais, econômicos e sociais, indispensáveis ao equilíbrio ecológico e à qualidade de vida da população (LAMAS, 1993). As áreas da cidade que possuem vegetação são mais valorizadas. Árvores, arbustos e outras plantas menores são elementos de composição e desenho urbano, que contribuem para organizar, definir e delimitar o espaço. Além disso, ajudam no controle do clima e poluição, conservação da água, redução de erosão e economia de energia (MASCARÓ; MASCARÓ, 2010).

A forma vegetal mais característica da paisagem urbana é a árvore. Além das contribuições citadas acima, a presença desse elemento gera benefícios psicológicos e sociais ao ser humano. A presença da arborização em bairros de alta densidade também auxilia na redução do medo e contribui para um comportamento menos violento e agressivo por parte de seus usuários, influenciando também na saúde psicológica e mental (MASCARÓ; MASCARÓ, 2010).

Segundo o Manual de Arborização de São Paulo (SÃO PAULO, 2015), a presença de árvores no meio urbano rompe com a monotonia das construções ao promover beleza cênica e trazer funcionalidade ao ambiente, aumentando a qualidade de vida da população. A nível do pedestre, as árvores são fundamentais para o conforto e habitabilidade urbana pois oferecem sombra, reduzem a temperatura do ambiente e induzem os efeitos do vento, além de protegerem pedestres e ciclistas ao influenciar na sensação de segurança contra os veículos em alta velocidade (SPECK, 2016).

Outra contribuição da arborização urbana é a formação de corredores ecológicos, interligando áreas verdes públicas ou particulares. Conforme disposto no Manual de Arborização de São Paulo (SÃO PAULO, 2015), esses corredores permitem conectar as populações de fauna e os fragmentos de vegetação, enriquecendo o ecossistema e aumentando a biodiversidade. Quando as áreas verdes e a arborização urbana se interconectam, formam uma rede ecológica, auxiliando na mitigação dos impactos da expansão urbana sobre a biodiversidade, bem como a formação de ilhas de calor. Esse mesmo sistema é definido por Mascaró (2012) como infraestrutura verde, responsável por reestruturar o mosaico da paisagem urbana.

Destaca-se ainda que a quantidade de vegetação urbana tem sido mensurada através de indicadores que expressam a superfície da área verde por habitante, como o Índice de Áreas Verdes (IAV). A Sociedade Brasileira de Arborização Urbana (SBAU, 1996) traz como proposta um índice mínimo de $15 \mathrm{~m}^{2}$ de área verde por habitante. Valor este que engloba apenas a disponibilidade de áreas verdes por habitante, desconsiderando a distribuição e o acesso (raio de influência) aos espaços verdes nas cidades.

Estocolmo, por exemplo, é considerada uma das cidades mais verdes do mundo, possui IAV de aproximadamente $86 \mathrm{~m}^{2} / \mathrm{hab}$., além disso, $90 \%$ da população tem acesso as áreas verdes em um raio de 300 metros em relação a suas residências; distância esta que representa um intervalo de tempo médio de 3 a 4 minutos de percurso a pé (PROGRAMA CIDADES SUSTENTÁVEIS, 2012).

\section{Caracterização Urbana da Região Central de Vila Velha}

A cidade de Vila Velha, localizada no litoral do estado do Espírito Santo, possui área de unidade territorial de $209,965 \mathrm{~km}^{2}$ sendo que, destes, apenas $54,57 \mathrm{~km}^{2}$ estão em perímetro urbano (IBGE, 2010). Ainda de acordo com o censo de 2010, sua população é de 414.586 habitantes, o que faz do município o segundo mais populoso do estado (IBGE, 2010). Limita-se a norte com o município de Vitória, capital do estado; a sul com Guarapari; a leste com o Oceano Atlântico e a oeste com os municípios de Viana e Cariacica, e para sua melhor organização, possui cinco regiões administrativas (Figura 1 ). 


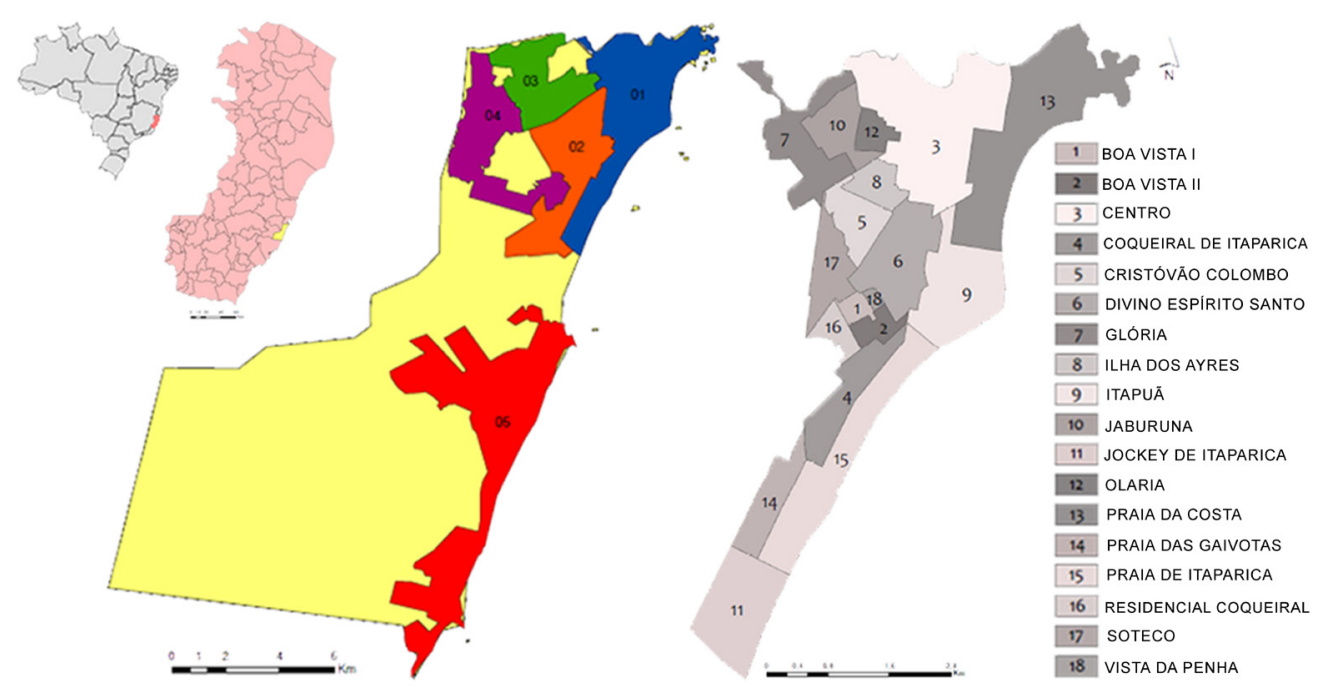

Figura 1. Localização do município de Vila Velha no contexto nacional e estadual. Na sequência, mapa do município evidenciando, em azul, a regional central e mapa da divisão em bairros. Fonte: Imagem gerada pelo ArcGIS, com base

De acordo com a Lei Municipal $n^{\circ}$ 4707/2008 (VILA VELHA, 2007), a Região Central (identificada na Figura 1 em azul) abrange 18 (dezoito) bairros da cidade. Sua área $\left(15,13 \mathrm{~km}^{2}\right)$ corresponde a $27,72 \%$ do perímetro urbano e sua população (147.279 hab.), equivale a $35,52 \%$ dos habitantes do município.

O Plano Diretor Municipal (VILA VELHA, 2007), em seu Zoneamento, cita que a Região Centro é constituída por Zonas de Ocupação Prioritárias (ZOP), Zonas de Proteção Ambiental e Cultural (ZEPAC), Zonas de Equipamento Especial (ZEE), Zona de Especial Interesse Urbanístico (ZEIU) e Zonas de Especial Interesse Ambiental (ZEIA), conforme ilustrado na Figura 2, a seguir. na Lei $n^{\circ} 4707 / 2008$, modificada pelas autoras, 2017.

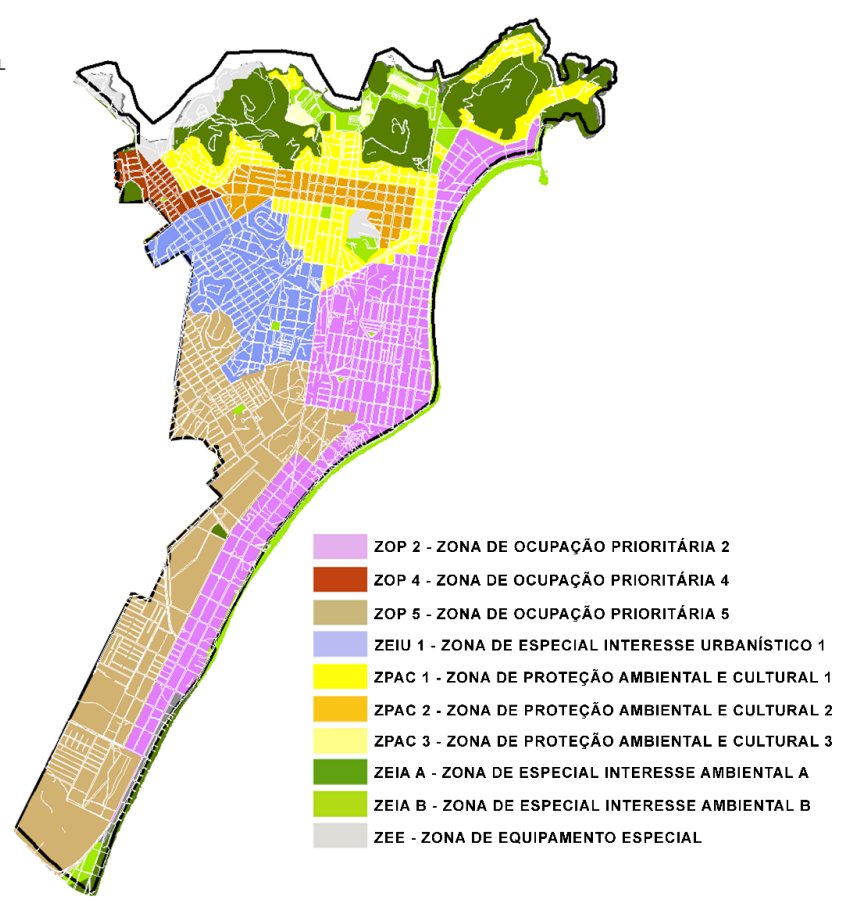

Figura 2. Mapa de Zoneamento urbano da Região Central de Vila Velha. Fonte: Plano Diretor Municipal, editado pelas autoras, 2018. 
A Região possui importantes monumentos naturais e culturais de interesse de preservação, com destaque para o Sitio Histórico da Prainha (ilustrado na Figura 3), as APPs situadas em relevo acentuado próximo ao litoral (Morro do Moreno, Convento da Penha e Morro de Jaburuna), além da orla das praias e dos canais retificados "Bigossi" e "da Costa".

A Regional Grande Centro é caracterizada por áreas em transformação urbana acelerada, com a maior concentração de adensamento vertical do município. Foi escolhida como recorte desta pesquisa por apresentar um processo constante e acelerado de transformação com supressão de áreas verdes potenciais. Essa transformação intensificou-se, a partir de década de 90, após a construção da Ponte Dep. Darcy Castello de Mendonça, conhecida por "Terceira Ponte" (destacada na Figura 4 em amarelo) - importante eixo viário metropolitano, responsável por conectar a cidade de Vila Velha à capital Vitória e demais cidades da Região Metropolitana da Grande Vitória (RMGV). Nota-se ainda, na sequência de imagens da Figura 4, que o adensamento de edifícios verticais próximos a essa nova ligação foi um fator determinante para a diminuição da área ocupada pela vegetação

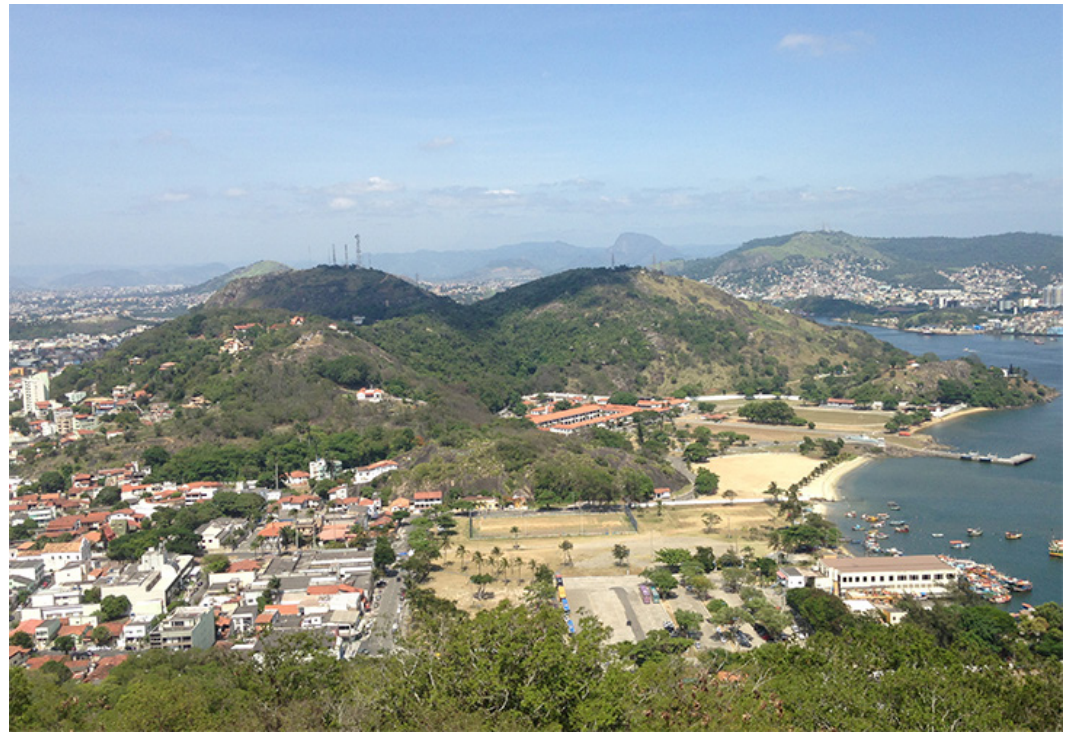

Figura 3. Vista aérea do Sítio Histórico da Prainha e das áreas de preservação situadas em relevo acentuado próximo ao litoral.

Fonte: Acervo do grupo Paisagem Urbana e Inclusão, 2018. natural da cidade.

Figura 4. Imagens aéreas da evolução urbana do entorno da Terceira Ponte, evidenciando o acelerado adensamento do município e consequente supressão de áreas verdes. Fonte: Veracidade e Google Earth, editado pelas autoras, 201

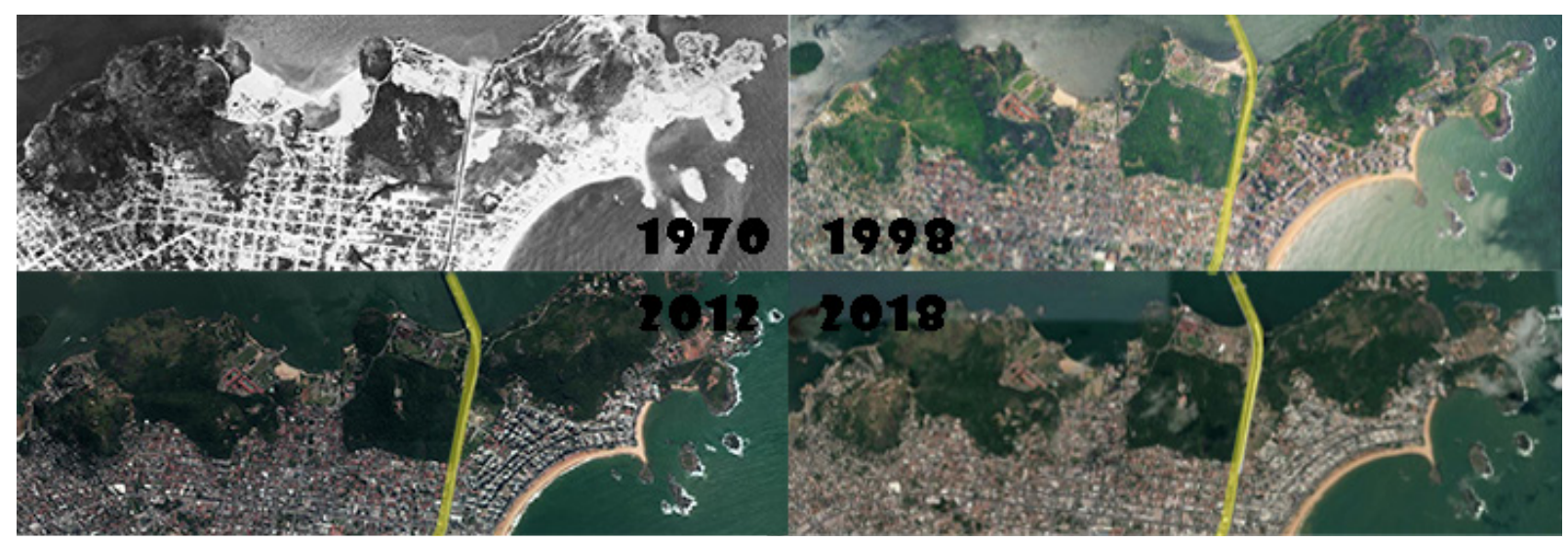


A Região Centro é também a regional de maior extensão territorial e densidade populacional. Atrai diariamente grande fluxo de pessoas devido à concentração de centros e subcentros comerciais, serviços públicos como a Prefeitura Municipal, o Fórum, o Ministério Público e a Agência da Previdência Social de Vila Velha, além da concentração de Shoppings Centers do município (Vila Velha, Boulevard e Praia da Costa) e também de instituições particulares como a Universidade e o Hospital Vila Velha.

\section{Espaços Livres de Equilíbrio Ambiental}

No âmbito deste trabalho, foi considerada a classificação de espaços de equilíbrio ambiental, utilizada por Mendonça (2015), que compreendem as áreas cobertas de vegetação significativa, envolvendo as Áreas de Preservação Permanente (APPs), as Unidades de Conservação e demais áreas verdes de valor paisagístico ambiental. Neste sentido, para o mapeamento dos espaços livres de equilíbrio ambiental da Regional Centro de Vila Velha foram consideradas as "Zonas Especiais de Interesse Ambiental (ZEIAs A) e terrenos com vegetação predominante, ou seja, aqueles considerados com áreas verdes de potencial paisagístico (AVPP). As "ZEIAs A", segundo o Plano Diretor vigente (VILA VELHA, 2007), englobam as APPs referente as áreas de relevo acentuado próximas à Baía de Vitória e a vegetação de restinga ao longo do litoral, conforme mapeamento ilustrado na Figura 5 em verde claro e escuro.

As áreas verdes de potencial paisagístico (AVPP) são áreas verdes particulares com potencial para transformação em parque público devido à extensa área verde preservada (MENDONÇA, 2015). Deste modo, alguns espaços privados foram identificados e mapeados como áreas verdes de potencial paisagístico (identificados na Figura 5 em laranja) por disporem de considerável área coberta de vegetação. Essas áreas, apesar de privadas, constituem pequenos espaços verdes benéficos para o ambiente urbano, passíveis de serem preservados, com significativo valor ambiental e com potencial para transformação em espaços livres públicos de equilíbrio ambiental.
Apesar da arborização urbana não ser classificadas por Mendonça (2015) como espaços livres de equilíbrio ambiental, no âmbito deste trabalho, também foram mapeadas as árvores de vias públicas, do calçadão, árvores da praia, praças e parques (identificadas na Figura 5 em amarelo) por compreender a importância da vegetação arbórea para o equilíbrio do ecossistema e da vivência urbana.

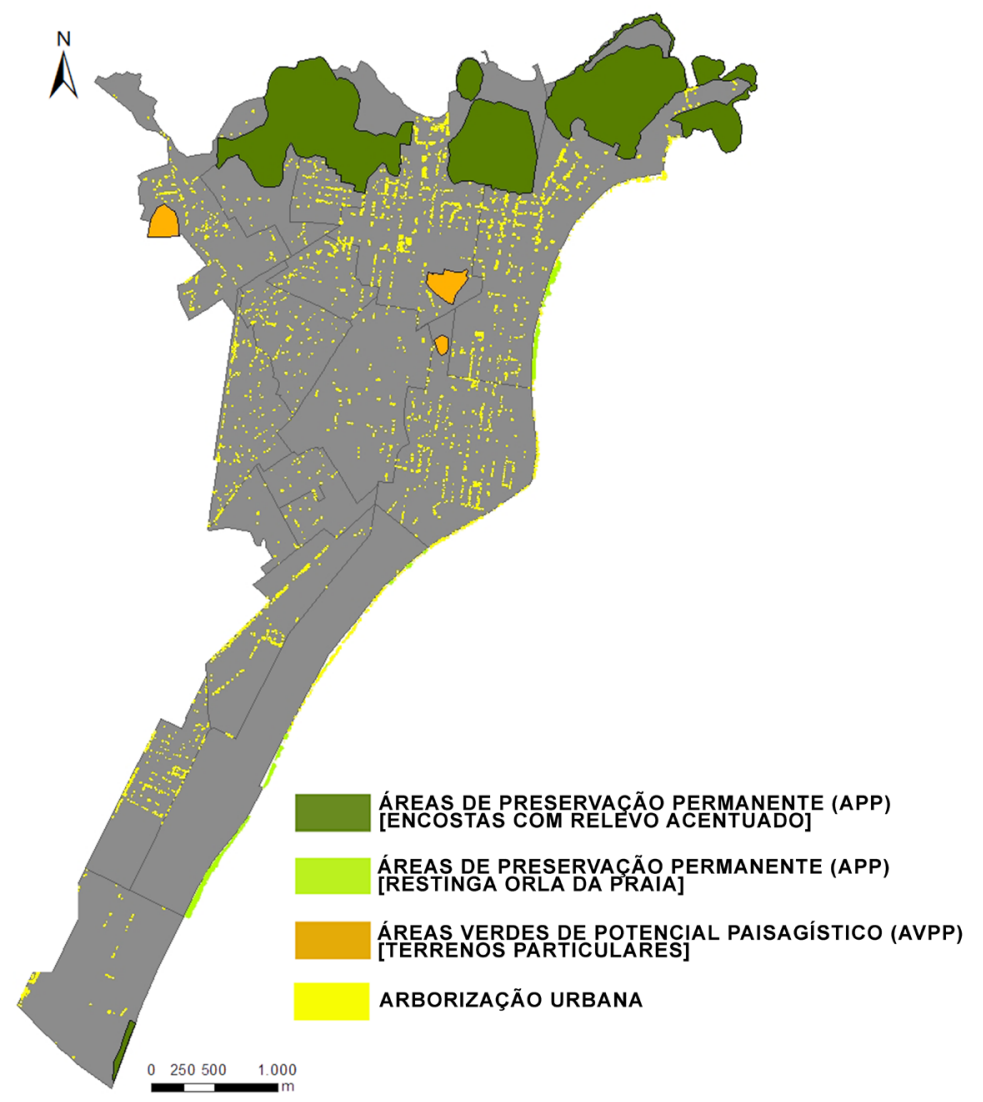

Figura 5. Mapeamento das áreas livres de equilíbrio ambiental e arborização urbana presentes na Regional Central de Vila Velha.

Fonte: Imagem gerada pelo ArcGIS, modificada pelas autoras, 2018. 
Para calcular as áreas de sombra promovidas pelas árvores das vias públicas e do calçadão, foram identificadas cada delas, no mapa base do programa ArcGIS, através de uma circunferência no tamanho aproximado da copa de cada árvore. Posteriormente, foram geradas tabelas no programa Excel para organização e análise dos dados e respectiva geração dos índices de áreas verdes (IAV).

\subsection{Leitura dos Índices de Áreas Verdes}

Conforme já citado, o índice de áreas verdes (IAV) indica a quantidade de área verde em metro quadrado por habitante. Após o mapeamento, foram gerados, nesta pesquisa, diversos IAVs, combinando diferentes cenários considerando: áreas de preservação permanente, áreas verdes de potencial paisagístico (AVPP), arborização de vias, calçadão, praia e praças (conforme combinação especificada na Tabela 1). Essa variação nos índices de áreas verdes foi gerada por não haver um consenso, entre autores, sobre quais desses espaços devem ser considerados para cálculo do IAV.
Consideradas todas as áreas verdes mapeadas, incluindo a arborização urbana e os espaços de equilíbrio ambiental (APP e AVPP), o índice da região (IAV 1) é de $16,97 \mathrm{~m}^{2} / \mathrm{hab}$. Apesar deste índice ser superior ao mínimo proposto pela SBAU $\left(15 \mathrm{~m}^{2} /\right.$ hab.), grande parte destes espaços são constituídos por áreas de preservação permanente, de acesso restrito à população, situada em encostas com relevo acentuado e infraestrutura de suporte aos usuários inadequada, além de serem espaços concentrados, privilegiando os bairros nas imediações.

Vale ainda ressaltar que o valor do IAV $1\left(16,97 \mathrm{~m}^{2} / \mathrm{hab}\right.$.) obteve esse resultado devido a predominância de áreas de preservação permanente entre os espaços de equilíbrio ambiental (consideradas ZEIAs pelo Plano Diretor Municipal), tendo sua preservação resguardada pela legislação. Os índices mostram também que, se excluídas as áreas de preservação permanente não existem espaços verdes significativos distribuídos entre os bairros da regional e o IAV reduz significativamente (IAV 5 de $2,70 \mathrm{~m}^{2} / \mathrm{hab}$ ). Esse fato demonstra que o poder público tende a manter os espaços verdes exigidos pela legislação, sem se preocupar com a criação de novos espaços verdes distribuídos

\begin{tabular}{|c|c|c|c|c|c|c|c|c|}
\hline \multirow{2}{*}{ IAV } & \multirow{2}{*}{$\begin{array}{c}\text { IAV } \\
\mathrm{m}^{2} / \mathrm{hab}\end{array}$} & \multicolumn{2}{|c|}{ APP $\left(\mathrm{m}^{2}\right)$} & \multicolumn{3}{|c|}{ Copa das Árvores $\left(\mathrm{m}^{2}\right)$} & \multirow{2}{*}{$\begin{array}{c}\text { AVPP } \\
\left(\mathrm{m}^{2}\right)\end{array}$} \\
\hline & & Encostas & Restinga & Vias públicas & Calçadão & Praia & Praças & $\checkmark$ \\
\hline IAV 1 & 16,97 & $\checkmark$ & $\checkmark$ & $\checkmark$ & $\checkmark$ & $\checkmark$ & $\checkmark$ & $\checkmark$ \\
\hline IAV 2 & 14,28 & $\checkmark$ & & & & & & \\
\hline IAV 3 & 16,18 & $\checkmark$ & $\checkmark$ & $\checkmark$ & $\checkmark$ & $\checkmark$ & $\checkmark$ & \\
\hline IAV 4 & 1,90 & & $\checkmark$ & $\checkmark$ & $\checkmark$ & $\checkmark$ & $\checkmark$ & \\
\hline IAV 5 & 2,70 & & $\checkmark$ & $\checkmark$ & $\checkmark$ & $\checkmark$ & $\checkmark$ & $\checkmark$ \\
\hline IAV 6 & 1,15 & & & $\checkmark$ & & & & \\
\hline IAV 7 & 1,50 & & & $\checkmark$ & $\checkmark$ & $\checkmark$ & $\checkmark$ & \\
\hline IAV 8 & 0,80 & & & & & & & $\checkmark$ \\
\hline IAV 9 & 14,70 & $\checkmark$ & $\checkmark$ & & & & & $\checkmark$ \\
\hline
\end{tabular}

Tabela 1. Áreas verdes consideradas para o cálculo de Índices de áreas verdes. A marcação através do "ü " indica o que foi considerado para geração de cada índice.

Fonte: Tabela gerada no Excel, produzida pelas autoras, 2018. 
pelos bairros para melhorar a vivência urbana e a qualidade de vida da população.

As APPs estão presentes em 6 (seis) dos 18 (dezoito) bairros que constituem a Regional Centro, são eles: Centro, Glória Jaburuna, Jockey de Itaparica, Olaria e Praia da Costa, não beneficiando diretamente os demais bairros. O Centro de Vila Velha é o bairro com o maior Índice de Áreas Verdes (IAV 1 de 141,25 m²/ hab, conforme representado na Tabela 2). Este número reflete a presença de Zonas Especiais de Interesse Ambiental (ZEIA), contempladas pelas APPs do Morro do Moreno, Convento da Penha e parte do Morro Jaburuna.

Se for considerado por bairro, é possível observar que o IAV1 dos bairros limítrofes às APPs (Centro, Glória, Jaburuna e Praia da Costa) alcançam valores mais satisfatórios, entretanto, os bairros mais afastados às Áreas de Preservação Permanente contabilizam índices próximos a zero. Por exemplo, os bairros Boa Vista I e Boa Vista II possuem, respectivamente, IAV1 de 0,38 e 0,35 $\mathrm{m}^{2} / \mathrm{hab}$., enquanto, no Centro, esse índice chega a 141,25 m²/hab.

\begin{tabular}{|c|c|c|c|}
\hline Bairros & Área (m2) & Popul ação (hab) & IAV $1\left(\mathrm{~m}^{2} / \mathrm{hab}\right)$ \\
\hline Boa Vista I & 91.190 & 3.143 & 0,38 \\
\hline Boa Vista II & 207.862 & 3.515 & 0,35 \\
\hline Centro & 2.563 .492 & 7.880 & 141,25 \\
\hline Coqueiral de Itaparica & 787.687 & 13.696 & 0,90 \\
\hline Cristóvão Colombo & 494.169 & 6.835 & 0,75 \\
\hline Divino Espírito Santo & 1.248 .045 & 8.031 & 0,75 \\
\hline Glória & 781.946 & 7.900 & 17,12 \\
\hline Ilha dos Ayres & 356.167 & 3.691 & 1,71 \\
\hline Itapuã & 1.075 .374 & 22.808 & 1,89 \\
\hline Jaburuna & 627.049 & 5.836 & 28,45 \\
\hline Jockey de Itaparica & 1.272 .120 & 2.393 & 13,05 \\
\hline Olaria & 244.920 & 1.596 & 4,33 \\
\hline Praia da Costa & 2.715 .610 & 31.083 & 28,61 \\
\hline Praia das Gaivotas & 324.022 & 6.282 & 1,82 \\
\hline Praia de Itaparica & 1.600 .313 & 11.648 & 5,18 \\
\hline Residencial Coqueiral & 218.365 & 1.554 & 0,62 \\
\hline Soteco & 481.072 & 8.189 & 1,17 \\
\hline Vista da Penha & 45.125 & 1.199 & 0,41 \\
\hline TOTAL REGIONAL 01 & 15.134 .528 & 147.279 & 16,97 \\
\hline
\end{tabular}


Nota-se, conforme evidenciado na figura 6, que poucos bairros atendem a disponibilidade mínima de áreas verdes por habitantes sugerida pela SBAU $\left(15 \mathrm{~m}^{2} / \mathrm{hab}\right)$. Apenas os bairros Centro $\left(141,25 \mathrm{~m}^{2} / \mathrm{hab}.\right)$, Glória $\left(17,12 \mathrm{~m}^{2} / \mathrm{hab}\right.$.), Jaburuna $\left(28,45 \mathrm{~m}^{2} / \mathrm{hab}\right.$.) e Praia da Costa $\left(28,61 \mathrm{~m}^{2} / \mathrm{hab}\right.$.) possuem IAV acima do mínimo proposto, devido à proximidade com as Áreas de Preservação Permanente (APPs).

É grande o impacto das APPs no cálculo do IAV tanto que, se forem consideradas somente as APPs das encostas, esse índice (IAV 2) é de $14,28 \mathrm{~m}^{2} / \mathrm{hab}$. Ou seja, considerando todas a áreas verdes mapeadas o índice é de $16,97 \mathrm{~m}^{2} / \mathrm{hab}$., mas, se considerado somente as APPs, o índice é de $14,28 \mathrm{~m}^{2} / \mathrm{hab}$., e sem a APP, o índice cai para $2,56 \mathrm{~m}^{2} /$ hab (IAV 5). Vale ressaltar que no cálculo do IAV, considerando somente as áreas de equilíbrio ambiental classificadas por Mendonça (2015), o índice de área verde (IAV 9 de $14,70 \mathrm{~m}^{2} / \mathrm{hab}$.) também não atinge o mínimo proposto pela SBAU.

Somando-se as áreas de sombras das árvores das vias públicas, calçadão, praia, praças e parques, o índice (IAV 7) é de apenas $1,50 \mathrm{~m}^{2} / \mathrm{hab}$. O IAV $6\left(1,15 \mathrm{~m}^{2} / \mathrm{hab}\right.$.) foi calculado considerando apenas as árvores de vias públicas e evidencia a precariedade da arborização urbana distribuída pelos bairros. Outra consideração, refere-se a abrangência das áreas de equilíbrio ambiental. Após o mapeamento, no entorno das áreas de preservação permanente (APP) e das áreas verdes de valor paisagístico (AVPP), foi demarcado um raio de 300 metros, com o objetivo de identificar a influência e a distribuição de tais áreas verdes, conforme ilustra a Figura 7.

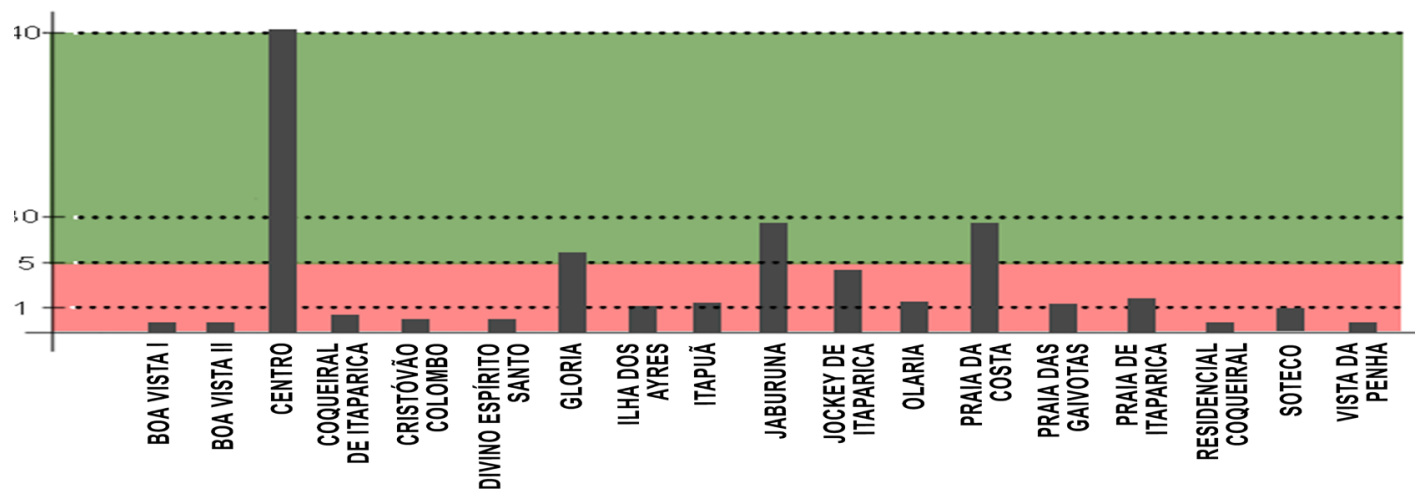

Figura 6. Gráfico de distribuição das áreas verdes por bairro da Regional Centro de Vila Velha. Fonte: Gráfico produzido no Photoshop, elaborado pelas autoras, 2017. 
As áreas verdes de valor paisagístico geram sozinhas um IAV de $0,8 \mathrm{~m}^{2} / \mathrm{hab}$. (IAV 8). Se for considerada a área total da Regional estudada, a abrangência destas áreas, considerado um raio de 300 metros no entorno das áreas de preservação permanente (APP) existentes, corresponde apenas $14,78 \%$; o que corrobora a necessidade de que sejam criadas novas áreas verdes acessíveis à população e distribuídas de forma homogênea entre os bairros. Se Incluídas as AVPP (evidenciadas em laranja na Figura 7) a abrangência alcança $21,76 \%$ da área total da Regional, aumentando a população beneficiada pelas áreas verdes.

\section{Identificação dos Espaços Livres Potencials}

No âmbito desta pesquisa, são considerados espaços livres potenciais os terrenos vazios, sem qualquer tipo de infraestrutura mas com potencialidades de serem trabalhados pelo poder público para incentivo e criação de novos espaços verdes (MENDONÇA, 2015).

Os terrenos potenciais foram identificados confrontando as áreas não contempladas pelo mapeamento das áreas livres de equilíbrio ambiental e suas áreas de abrangência, considerando o raio de influência de 300 metros das áreas de equilíbrio ambiental existente para instalação de novas áreas verdes, preenchendo os espaços deficientes, conforme ilustrado na Figura 8.

Os terrenos potenciais, evidenciados em laranja na Figura 8, são de extrema importância para melhor distribuir a presença de áreas verdes, equilibrando a concentração destas áreas em toda a regional, além de contribuir para a melhoria da vivência urbana da população. Acredita-se que caso os espaços potenciais forem transformados em áreas verdes poderão propiciar a formação de corredores ecológicos juntamente com as áreas de preservação permanente existentes. Para isso, seria necessário arborizar as vias que interligam essas áreas, com árvores de espécies adequadas para o ambiente urbano e espaçamento mínimo entre elas.

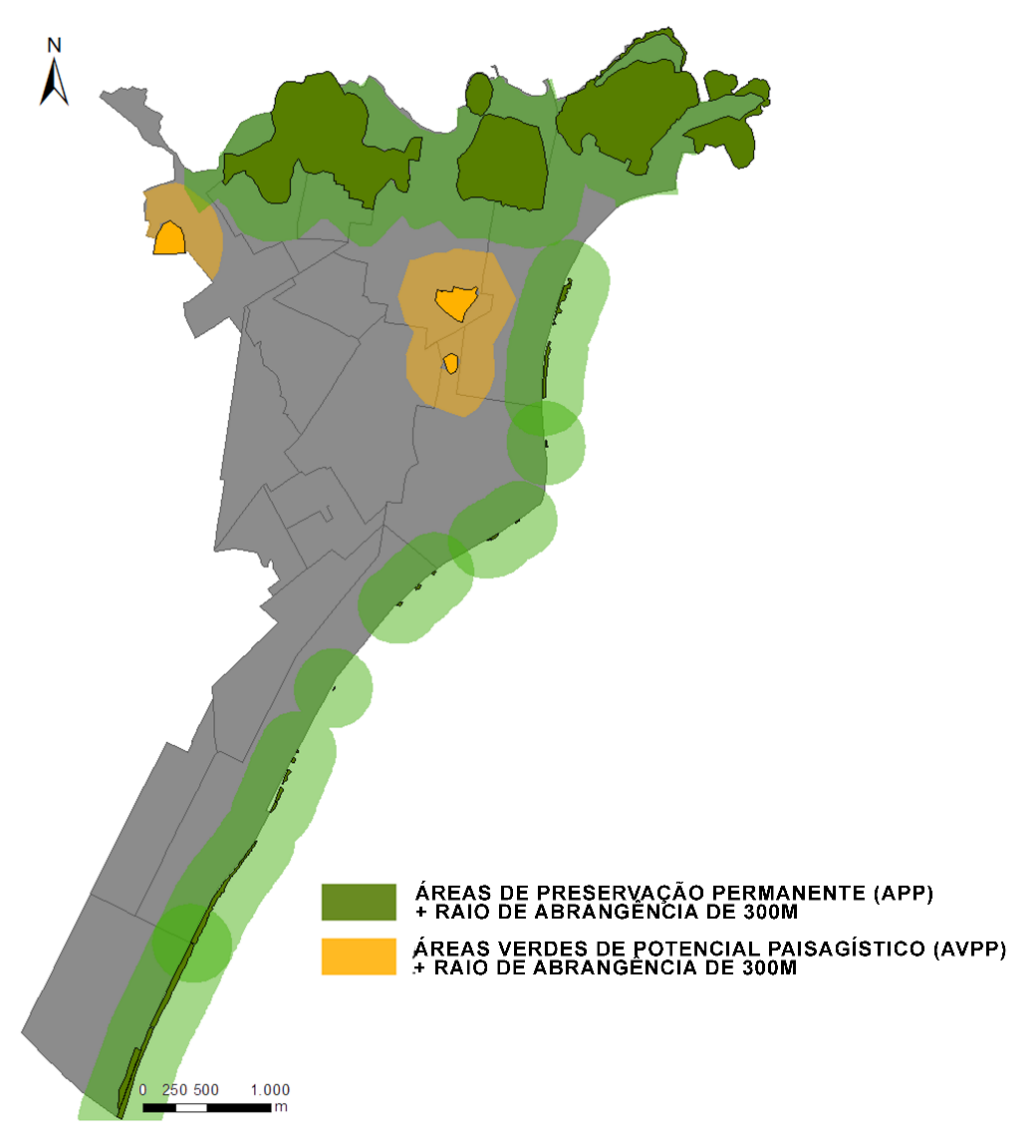

Figura 7. Mapeamento dos espaços de equilíbrio ambiental (APPs e AVPP) e abrangência considerando raio de 300 metros.

Fonte: Imagem gerada pelo ArcGIS, modificada pelas autoras, 2018. 


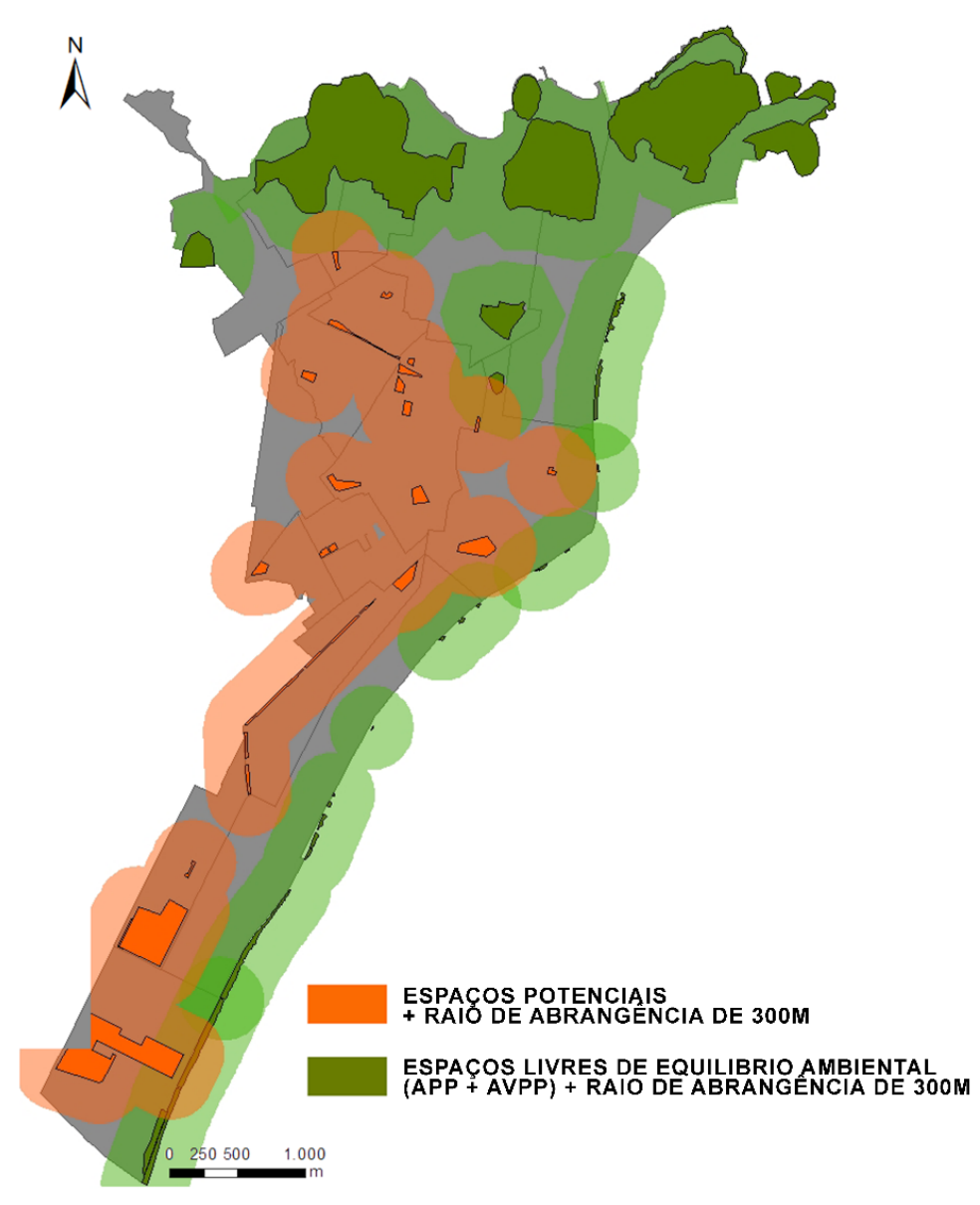

Figura 8. Mapeamento dos espaços livres de equilíbrio ambiental (APPs + AVPPs), dos terrenos potenciais e sua abrangência, considerando o raio de 300 metros. Fonte: Imagem gerada pelo ArcGIS, modificada pelas autoras, 2018.
Como exposto, com exceção das áreas de preservação permanente, os demais espaços são potenciais. As áreas verdes de potencial paisagístico (AVPP) já são cobertas por vegetação considerável, mas por serem áreas particulares, não são consideradas áreas de interesse ambiental pelo município. As praças, parques e calçadão, apesar de espaços públicos, não dispõem de área verde suficiente, havendo necessidade do plantio de árvores e outras espécies vegetais. Os espaços potenciais são áreas particulares, carentes de vegetação que precisariam ser desapropriadas pelo Poder Público para transformação em áreas verdes.

\section{Condições para Aumento das Áreas Verdes}

Os resultados gerados na pesquisa indicam a necessidade de intervenção no sentido de aumentar as áreas verdes visando promover melhoria na vivência urbana e na qualidade ambiental da Regional Central do município de Vila Velha. A fim de contribuir para a eficiência dessas intervenções, sugerem-se a seguir algumas proposições:

- Inserir um Plano de Arborização Urbana nos novos projetos de loteamento visto que a Lei de Parcelamento do Solo (BRASIL, 1979) não trata de tal assunto. Com a arborização de vias públicas, praças e parques seria possível indicar locais adequados ao plantio e espécies específicas para cada situação. Também seria fundamental que o município desenvolvesse um manual de arborização urbana, especifico para a cidade de Vila Velha.

- Incluir no projeto municipal "Calçada Legal" - Guia prático para construção, reforma e conservação das calçadas (VILA VELHA, 2014) - orientações para o plantio de árvores nas calçadas. A quantidade e espécies seriam avaliadas de acordo com o tamanho das vias e o clima local.

- Nas situações em que a largura da calçada não comporte o plantio de árvores, trabalhar a alternativa de plantá-las em locais do leito carroçável destinados 
aos estacionamentos de veículos, como extensão da própria calçada, mantendo um número razoável de vagas para estacionamento e promovendo a qualidade ambiental das vias públicas através da arborização. Os canteiros, exemplificados na Figura 9, são exemplos de extensão da calçada em locais que a princípio seriam destinados a estacionamento de veículos. No caso de calçadas estreitas, canteiros desse modelo poderiam ser a solução para a arborização das vias públicas.
- Para construções de grande porte, dentre elas os edifícios verticais multifamiliares, incluir no Estudo de Impacto de Vizinhança (EIV), a avaliação do impacto ambiental e paisagístico do entorno. O EIV pode estabelecer um modo de compensação ambiental da degradação ocorrida no terreno do empreendimento, como o corte de árvores, por exemplo. Além disso, pode prever afastamentos frontais maiores para que sejam realizados tratamentos paisagísticos que beneficiem a qualidade ambiental da cidade.
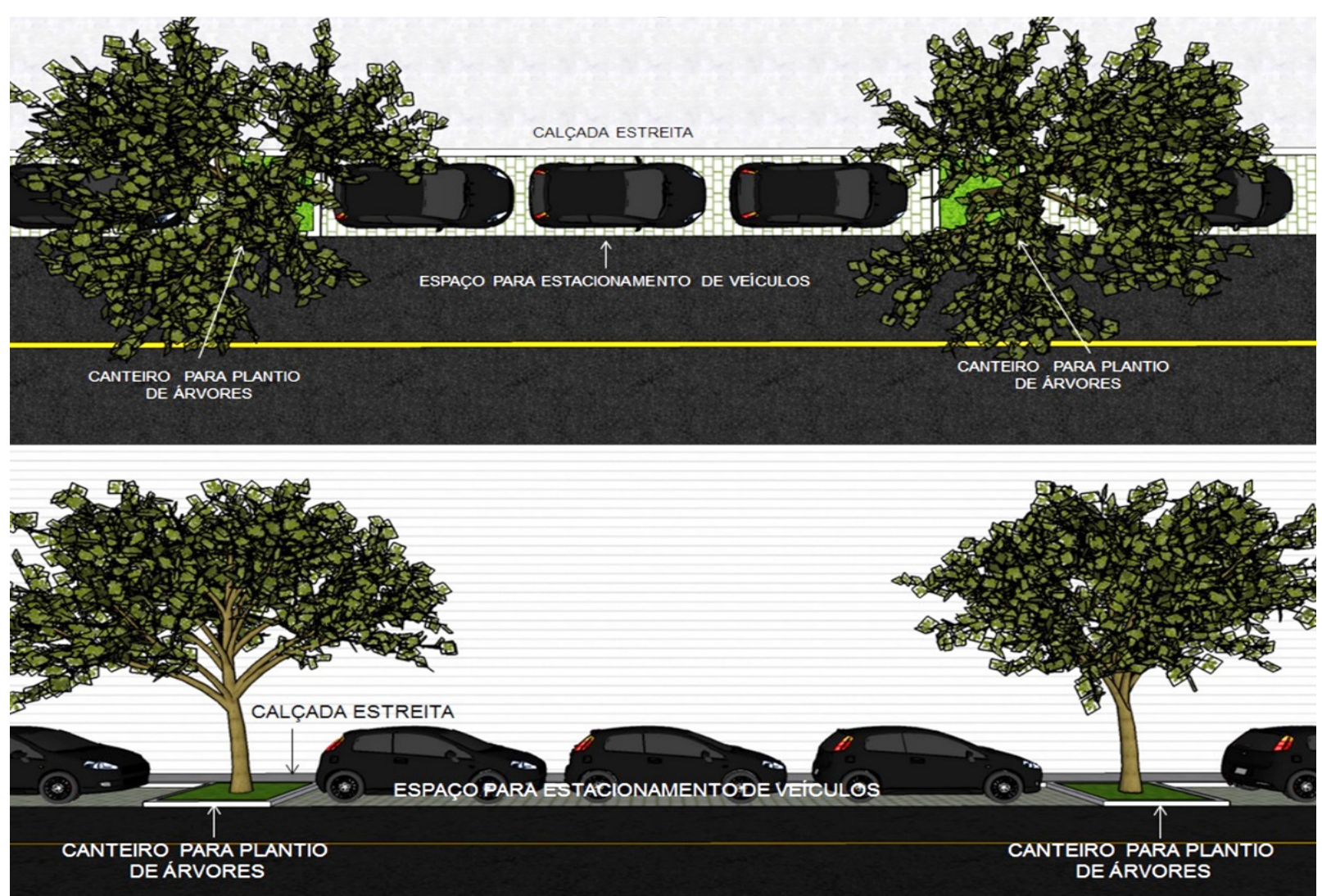

Figura 9. Croquis exemplificando os canteiros para arborização de vias públicas situados nos espaços de estacionamento.

Fonte: Imagens elaboradas no SketchUp pelas autoras, 2018 
- Estabelecer porcentagem mínima de área verde em praças e parques, além de porcentagem mínima de área permeável do terreno no afastamento frontal afim de promover a urbanidade e caminhabilidade em vias públicas, estimulando, além da permeabilidade do solo, o tratamento paisagístico nesses espaços e o aumento do conforto térmico e da qualidade estética urbana;

- Conceber novos espaços verdes distribuídos de forma homogênea no município utilizando para isso os espaços potenciais mapeados neste trabalho.

- Estimular o plantio de árvores em estacionamentos de grandes empreendimentos privados e públicos como shoppings centers, aeroportos, hospitais e escolas.

\section{Conclusão}

A pesquisa demonstra, através do mapeamento das áreas de equilíbrio ambiental da Regional Central do município de Vila Velha, que estas não atendem homogeneamente à população, pois se concentram em poucos bairros da cidade, em áreas de relevo acentuado, próximas à Baía de Vitória. Nos demais bairros faltam espaços verdes e, em toda a região, a arborização é precária.

Considerado um raio de abrangência de 300 metros a partir das áreas de preservação permanente, observa-se uma baixa porção territorial contemplada por essas áreas. A área de influência aumenta quando consideradas as áreas verdes de potencial paisagístico (AVPP), evidenciando, assim, a necessidade de projetos que transformem essas áreas em zonas de interesse ambiental pelo município. Apesar de particulares e inacessíveis, as AVPP beneficiam a cidade em razão da área de vegetação disponível.

Ainda foram identificados, em diversos pontos da regional, terrenos potenciais possíveis de serem transformados em espaços verdes acessíveis a população. Se parte destes terrenos fossem transformados em áreas verdes, seria possível abranger toda a Regional Central do município de forma melhor distribuída, aumentando, significativamente, a qualidade ambiental, além de criar espaços para práticas sociais.

Indiscutível a importância das APPs, no entanto, como já exposto, elas se concentram em regiões específicas abrangendo pequena parte da Regional. As árvores de vias públicas deveriam ser em maior quantidade, contribuindo para controle de temperatura na cidade, melhoria da qualidade do ar, desenvolvimento do ecossistema local, além de benefícios psicológicos dos moradores e frequentadores, promovendo também benefícios estéticos para a cidade.

Os mapas e tabelas gerados constituem fonte de dados para possíveis futuras intervenções na concepção de espaços livres de uso público para o município de Vila Velha, visando aumentar a qualidade de vida da população no aspecto urbano, ambiental e, por consequência, social, pois as áreas verdes podem ser espaços públicos de convivência.

Recomenda-se um aprofundamento nos estudos visando o desenvolvimento de um sistema de áreas verdes para o município, com diversidade de uso e consumo, com espaços destinados a um público local e também espaços de abrangência regional, municipal e até metropolitano.

\section{ReferênCIAS Bibliográficas}

AGUIAR, Douglas; NETTO, Vinicius M (org). Urbanidades. Rio de Janeiro: Folio Digital: Letra e Imagens, 2012.

ANDRADE, Victor. LINKE, Clarisse Cunha. Cidades de pedestres: A caminhabilidade no Brasil e no mundo. Rio de Janeiro: Babilônia Cultural Editorial, 2017.

BRASIL. Lei n. 6.766, de 19 de dezembro 1979. Lei de Parcelamento do Solo. Brasilia-DF, dez. 1979 .

BRASIL. Ministério do Meio Ambiente. Conselho Nacional do Meio ambiente, CONAMA. Resolução CONAMA $n^{\circ}$ 369, de 28 de março de 2006. Disponível em: <http://www.mma.gov. br/port/conama/legiabre.cfm?codlegi=489> Acesso em: 23 julho 2018.

GEHL, Jan. Cidades para pessoas. São Paulo, SP: Perspectiva, 2015. 
IBGE. Instituto Brasileiro de Geografia e Estatística. Censo demográfico 2010. Características da população e dos domicílios: resultados do universo. Rio de Janeiro: IBGE, 2010.

LAMAS, J. M. R. G. Morfologia urbana e desenho da cidade. Fundação Calouste Gulbenkian, 1993

LIMA, Ana Maria Liner Pereira. CAVALHEIRO, Felisberto. NUCCI, João Carlos. SOUZA, Maria Alice de Lourdes Bueno. FIALHO, Nilva de Oliveira. PICCHIA, Paulo Celso Dornelles Del. Problemas de utilização na conceituação de termos como espaços livres, áreas verdes e correlatos. In: Il Congresso Brasileiro de Arborização Urbana 1994. São Luiz/MA. Anais... São Luiz: Imprensa EMATER/MA, 1994. p. 539553.

LIMA, Valéria. AMORIM, Margarete Cristiane de Costa Trindade. A importância das áreas verdes para a qualidade ambiental das cidades. Revista Formação, nº13, p. $139-165,2006$. Disponivel em:<http://revista.fct.unesp.br/index.php/formacao/article/viewFile/835/849> Acesso em: 16.02.2016.

MASCARÓ, Juan José. A Infraestrutura Verde Como Estratégia de Sustentabilidade Urbana. In: Encontro Nacional de Tecnologia do Ambiente Construído (XIV ENTAC) 2012, Juiz de Fora. Anais... Juiz de Fora: UFMG, 2012, p. 962-969. Disponível em: <http://www.infohab.org.br/ entac2014/2012/docs/1032.pdf> Acesso em: 06.04.2018.

MASCARÓ, Juan Luis (org.). Infra-estrutura da Paisagem. Porto Alegre: Masquatro editora 2008

MASCARÓ, Juan Luis; MASCARÓ, Lucia. Vegetação Urbana. Porto Alegre: Masquatro Editora, 2010

MENDONÇA, E. M. S. A importância metropolitana do sistema de espaços livres da região de Vitória - ES - Brasil. EURO ELECS 2015, Guimarães, Portugal. In Anais EURO ELECS 2015 Guimarães, Portugal, Vol. III, 2015.

NETTO, Vinicius M; SABOYA, Renato T. de; VARGAS, Júlio Celso; CARVALHO, Thereza (org.) Efeitos da arquitetura: os impactos da urbanização contemporânea no Brasil. Brasília: FRBH, 2017

NUCCI, João C. Qualidade ambiental e adensamento urbano. Curitiba: UFPR, E-book, 2008.

PROGRAMA CIDADES SUSTENTÁVEIS. Metas de Sustentabilidade para os Municípios Brasileiros (Indicadores e Referências). Rede Nossa São Paulo. Rede Social Brasileira por Cidades Justas e Sustentáveis. Instituto Ethos de Empresas e Responsabilidade Social. 2012.

SÃO PAULO. Secretaria Municipal do Verde e do Meio Ambiente. Manual Técnico de Arborização Urbana. 3. Ed. São Paulo: Gráfica Ibraphel, 2015.

SBAU. Sociedade Brasileira de Arborização Urbana. Carta de Londrina e Ibiporã. Boletim Informativo, v.3, n.5, p.3, 1996

SHULTZ, Sonia. Estéticas urbanas: da pólis grega à metrópole contemporânea. Rio de Janeiro: LTC, 2008 .

SPECK, Jeff. Cidade caminhável. São Paulo, SP: Perspectiva, 2016.

VILA VELHA. Lei n ${ }^{\circ} 4.575$ de 26 de novembro de 2007. Plano Diretor Municipal de Vila Velha. Prefeitura Municipal de Vila Velha. Vila Velha-ES, 2007.

VILA VELHA. Lei $n^{\circ} 4.707$ de 10 de setembro de 2008. Institucionalização dos bairros nas Regiões Administrativas, os limites e a denominação dos mesmos e os criterios para organização e criação de bairros, no perímetro urbano do Município. Prefeitura Municipal de Vila Velha, Vila Velha-ES 2008.
VILA VELHA. Secretária Municipal de Desenvolvimento Urbano. Calçada legal. Guia prático para construção, reforma e conservação das calçadas. Vila Velha-ES, 2014. Disponível em:

Larissa Leticia Andara Ramos

Universidade Vila Velha (UVV), Programa de pós-graduação em Arquitetura e Cidade (PPGAC).

Campus Boa Vista, Av. Comissário José Dantas de Melo, n²1, Vila Velha, ES, Brasil, CEP 29102-920

CV: http://lattes.cnpq.br/2687764478783021

Orcid: https://orcid.org/0000-0002-2295-8995

E-mail: larissa.ramos@uvv.br

\section{Patrícia Scarpat Thompson Palhano}

Universidade Vila Velha (UVV), Curso de graduação em Arquitetura e Urbanismo.

Campus Boa Vista, Av. Comissário José Dantas de Melo, $n^{\circ} 21$, Vila Velha, ES, Brasil, CEP 29102-920

CV: http://lattes.cnpq.br/1027578647832062

Orcid: https://orcid.org/0000-0002-3057-2638

E-mail: patstpalhano@gmail.com

\section{Suzany Rangel Ramos}

Universidade Vila Velha (UVV), Programa de pós-graduação em Arquitetura e Cidade (PPGAC).

Campus Boa Vista, Av. Comissário José Dantas de Melo, $n^{\circ} 21$, Vila Velha, ES, Brasil, CEP 29102-920

CV: http://lattes.cnpq.br/9224393411668015

Orcid: https://orcid.org/0000-0001-7011-2591

E-mail: suzany.r@hotmail.com

\section{Nota do Editor}

Submetido em: 23/07/2018

Aprovado em: 08/03/2019

Revisão do texto: Tikinet 